\title{
Crystallization and Melting Behavior of Nylon 66/Poly(ether imide) Blends
}

\author{
Jae Heung LeE, Sung-Goo LeE, Kil-Yeong ChOI, and Jingjiang LiU \\ Advanced Materials Division, Korea Research Institute of Chemical Technology, P.O. Box 107, Yusong, Taejon 305-600, Korea \\ * Changchun Institute of Applied Chemistry, Chinese Academy of Sciences, \\ Changchun 130022, People's Republic of China
}

(Received May 26, 1997)

\begin{abstract}
Isothermal crystallization and melting behavior of nylon 66 and its blends with poly(ether imide) (PEI) were investigated by differential scanning calorimetry. Crystallization kinetics such as overall rate constant $Z$ and index $n$ were calculated according to Avrami approach. Crystallization in the blend was retarded with respect to that of pure nylon 66 by incorporation of PEI with high glass transition temperature $\left(T_{\mathrm{g}}\right)$. The lowest growth rate of the spherulites was observed in the blends containing 10 and $15 \mathrm{wt} \%$ fraction of PEI. A transition temperature where positively birefringent spherulites disappear and negative birefringent spherulites develop was measured by thermal analysis. The transition temperature increased with content of PEI in the blends. A suitable range of isothermally crystallization temperatures, $238.5-246^{\circ} \mathrm{C}$, is suggested for determining the equilibrium melting points by means of Hoffman-Weeks approach. KEY WORDS Crystallization Behavior / Melting / Polymer Blend / Nylon 66/Poly(ether imide) /
\end{abstract}

Poly(ether imide), PEI, (poly(2,2'-bis(3,4-dicarboxyphenoxy)phenyl propane)-2-phenylene bisimide), is a relatively new high performance material with the repeat unit:

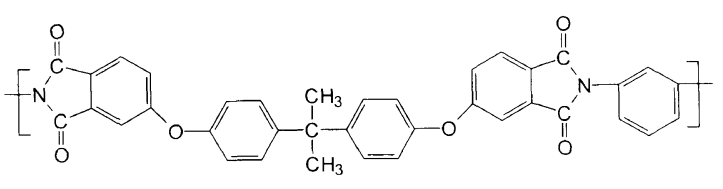

It is a thermally stable, non-crystallizable and soluble thermoplastic manufactured by General Electric Co. Key properties of PEI are excellent high temperature resistance, toughness, good dielectric properties, low flammability, and high resistance to radiation and deformation under load at elevated temperatures. In particular, PEI combines relatively low production cost with appreciable physical properties. ${ }^{1-3}$ Some basic research on the blends of PEI with thermotropic liquid crystalline polymers, ${ }^{4}$ polyetheretherketone,${ }^{5}$ polyethersulfone, ${ }^{6}$ and polybenzimidazole ${ }^{7}$ has been carried out.

Aliphatic polyamides are extensively used in the manufacture of automobile parts, engineering products, and textile fibers. Among various polyamides, nylon 66 and nylon 6 are commercially important polyamides. Nylon 66 is a crystallizable material with relatively high mechanical properties, low cost, and low melting viscosity. Blending nylon 66 with a variety of polymers has generated considerable interest because this is an easy way of tailoring nylon 66 to suit specific end uses. Sometimes, it made blends of nylon 66 with novel mechanical performance and excellent processing properties. Significant improvement in processing properties of PEI can be achieved without a consequent decrease in the mechanical properties by blending a small amount of nylon 66 with PEI. The mechanical and heat resistant properties of nylon 66 increase remarkably by adding PEI as a minor component. Thus, blending the two polymers seems most attractive in terms of both processability and performance improvement.

Numerous works have been reported on polyamides regarding melting behavior, ${ }^{8,9}$ crystal structures, ${ }^{10,11}$ spherulitic morphologies, ${ }^{12,13}$ as well as the reorganization of crystals on heating, ${ }^{14}$ but study of crystallization and melting behavior of nylon blends, in particular, with heat resistant polyimides, is not so much. ${ }^{15}$

In the first article of this series, we examined the binary polymer blends consisting of nylon 66 and PEI. The rheology, dynamic mechanical properties, morphology, and the degree of crystallinity of the blends in the whole range of the composition have been studied. ${ }^{16}$ The blends appeared to have phase-separated structures with the domains in the order of sub-micrometer. The inward shifted $T_{\mathrm{g}} \mathrm{s}$ in the blends compared with those of homopolymers were detected on the dynamic mechanical spectra. The relative weight fraction of PEI mixed into nylon 66-rich phase increased with decreasing PEI in these blends, which might result from the formation of intermolecular interaction between the two components. ${ }^{16}$

In this investigation, the contents of nylon 66 in the blends were more than $50 \%$ by weight to ensure for the polyamide to be the continuous phase. The blends of nylon 66 with $5,10,15,25$, and $50 \mathrm{wt} \%$ fractions of PEI were prepared. The crystallization kinetics and melting behavior were investigated as a function of the blend composition and crystallization temperature. Changes in the crystallization parameters from Avrami approach and in spherulite structures are discussed in terms of molecular interaction and crystallization temperature.

\section{EXPERIMENTAL}

\section{Materials}

PEI was manufactured by General Electric Co., Pittsfield, MA, as pellets; the resin is commercially available as Ultem 1000 with $1.27 \mathrm{~g} \mathrm{~cm}^{-3}$ of the density. Nylon 66, Toplamid 2021, was supplied by Tongyang Nylon Co., Korea, as pellets. The manufacturer reports the density as $1.14 \mathrm{~g} \mathrm{~cm}^{-3}$ and the melting point as $255^{\circ} \mathrm{C}$. Both nylon 66 and PEI absorb moisture easily. Before use they were dried at $90^{\circ} \mathrm{C}$ for $24 \mathrm{~h}$. 


\section{Sample Preparation}

An internal mixer (Haake Rheocord 90) was used to prepare blends. Both mixing speed and temperature were controlled. Typically, a $50 \mathrm{~g}$ sample was mixed at $60 \mathrm{rpm}$ for about $10 \mathrm{~min}$ at $300^{\circ} \mathrm{C}$, until an equilibrium torque was approached. The same processing procedure was followed for pure nylon 66. Samples were removed hot from the mixer, rapidly cooled to room temperature and stored in a desiccator prior to use.

The weight ratios of PEI and nylon 66 are as follows: $0 / 100,5 / 95,10 / 90,15 / 85,25 / 75$, and $50 / 50$ coded as PEI 0 , PEI 5 , and so on.

\section{Methods of Investigation}

In the kinetics on isothermal crystallization as a function of blend composition and temperature, a differential scanning calorimeter (Perkin Elmer DSC-7) working under dry nitrogen atmosphere and calibrated in temperature and heat flow scales following the standard procedures, was used to detect thermal transitions and to monitor the rate of heat flow from the sample during isothermal crystallization. $10 \pm 2 \mathrm{mg}$ of sample was placed in a DSC pan and quickly heated to $300^{\circ} \mathrm{C}$ and held for $5 \mathrm{~min}$ to eliminate the memory of the previous thermal and mechanical history and followed by rapid cooling at $200^{\circ} \mathrm{C} \mathrm{min}^{-1}$ by nitrogen gas flow to a selected crystallization temperature, $T_{\mathrm{c}}$, where an isothermal crystallization experiment was carried out. The heat generated during the development of the crystalline phase was recorded and analyzed according to the usual procedure to calculate the relative degree of crystallinity, $\alpha(t)$ :

$$
\alpha(t)=\frac{\int_{t_{0}}^{t}\left(\frac{\mathrm{d} H}{\mathrm{~d} t}\right) \mathrm{d} t}{\int_{t_{0}}^{t_{\infty}}\left(\frac{\mathrm{d} H}{\mathrm{~d} t}\right) \mathrm{d} t}
$$

where $t_{0}$ is the time at which the sample attains isothermal conditions, as indicated by a flat baseline after the initial spike on the thermal curve, and $t_{\infty}$ is the time at the end of the crystallization.

The absolute degree of crystallinity of nylon 66 in the blend, $\chi(t)$, was calculated from the heat evolved during crystallization by means of the relationship:

$$
\chi(t)=\frac{\int_{t_{0}}^{t}\left(\frac{\mathrm{d} H}{\mathrm{~d} t}\right) \mathrm{d} t}{\Delta H_{\mathrm{m}}^{\mathrm{o}} W_{2}}
$$

where $\Delta H_{\mathrm{m}}^{\mathrm{o}}=188.1 \mathrm{~J} \mathrm{~g}^{-1}$ is the melting enthalpy change of perfect nylon 66 crystal $^{7}$ and $W_{2}$ is the weight fraction of nylon 66 in the blend.

The melting behavior of the sample was studied after an isothermal crystallization experiment was carried out by heating the sample in a DSC pan from $T_{\mathrm{c}}$ directly.

\section{RESULTS AND DISCUSSION}

The blends of PEI and nylon 66 have phase-separated structures with domain size of the order of $10^{-1} \mu \mathrm{m}$ in the previous paper with some degree of interaction between the components. ${ }^{16}$

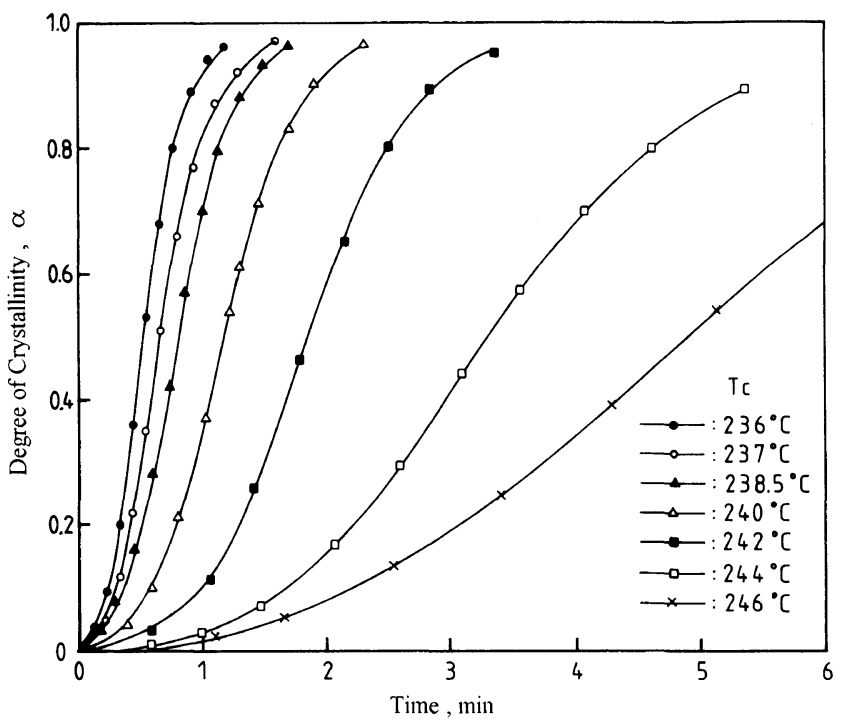

Figure 1. Relative degree of crystallinity, $\alpha$, vs. time plots under isothermal crystallization at different $T_{\mathrm{c}}$ s for pure nylon 66 .

Crystallization kinetics in a phase-separated polymer blend shows very complex phenomena related to the production of primary nuclei, formation and spreading of bidimensional surface nuclei, interdiffusion of crystallizable and non-crystallizable chains at the advancing front of the growing crystal and engulfment/rejection of small domains of a non-crystallizable component.

Fortunately, phenomenological study on isothermal crystallization of PEI/nylon 66 blend, a partially miscible system with domain size of the order of $10^{-1} \mu \mathrm{m}$, can be carried out according to Avrami approach. Crystallization nucleation, interaction of components, and growth rate of spherulite can be explained qualitatively by kinetic parameters.

According to phenomenological theory, the relative degree of crystallinity, $\alpha(t)$, at time $t$ in isothermal conditions is given by:

$$
\alpha(t)=1-\exp \left(-Z t^{n}\right)
$$

where $n$ is the Avrami exponent and $Z$ is the overall rate constant containing nucleation and growth contributions. Typical plots of $\alpha$ as a function of crystallization time $t$ at different $T_{\mathrm{c}}$ are shown in Figures 1 and 2 for pure nylon 66 and PEI 15, respectively. From these curves, the half time of crystallization, $t_{1 / 2}(\alpha=0.5)$ was measured and is shown in Figure 3.

The Avrami parameters, $Z$ and $n$ are obtained for each crystallization temperature $T_{\mathrm{c}}$ from the $y$-intercept and slope of the plot of $\log [-\ln (1-\alpha)] v s . \log t$, respectively. The best straight line fitting the experimental points is shown at low transformation. The points deviated from the straight lines are not appropriate because the secondary crystallization is not treated in the Avrami approach.

Figures 4 and 5 illustrate the plots of rearranged eq 3 for pure nylon 66 and PEI 15, respectively, under different $T_{\mathrm{c}}$ s ranging from 236 to $246^{\circ} \mathrm{C}$. The overall crystallization rate constant $Z$ and Avrami exponent $n$ are listed in Table I together with $t_{1 / 2}$ for all blends investigated. Avrami exponent $n$ is in the range of 2.6-3.0 for pure 


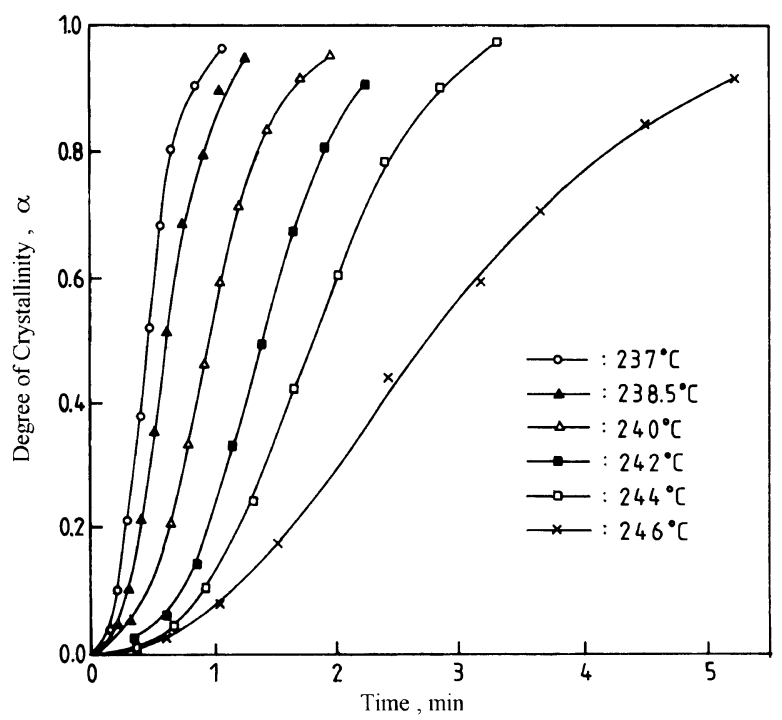

Figure 2. Relative degree of crystallinity, $\alpha$, vs. time plots under isothermal crystallization at different $T_{\mathrm{c}} \mathrm{s}$ for PEI 15.

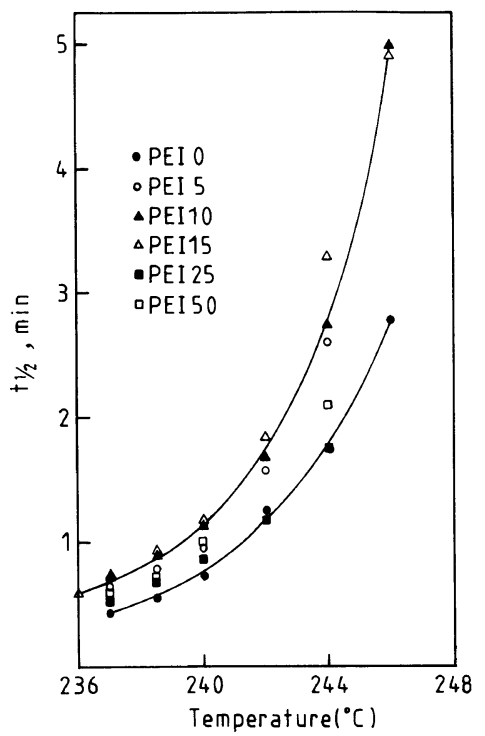

Figure 3. Half-time of crystallization $(\alpha=0.5)$ of the blends as a function of $T_{\mathrm{c}}$ at various compositions for the blends of nylon 66/PEI.

nylon 66 and 2.3-3.0 for the blends, meaning that there are no significant changes in the Avrami exponent $n$ for pure nylon 66 and the blends because the small change of the exponent $n$ in the range of $0.2-0.3$ is trivial in Avrami analysis.

From the results in Figure 3 and Table I, it can be seen that the crystallization process in the blends is somewhat retarded with respect to the pure nylon 66 , especially for PEI 10 and PEI 15. The depression of the crystallization rate observed experimentally can be explained according to Hoffman's nucleation theory. The relationship between spherulite linear growth rate $G$, and Avrami parameters, $Z$ and $n$, reads:

$$
G \propto Z^{1 / n}
$$

It is clearly concluded from the plots of $1 / n \log Z$ as a function of $T_{\mathrm{c}}$ at various compositions shown in Figure 6 that pure nylon 66 exhibits the highest linear growth rate of spherulites, while the lowest is shown in PEI 10 and PEI 15 and that the intermediate values scattered

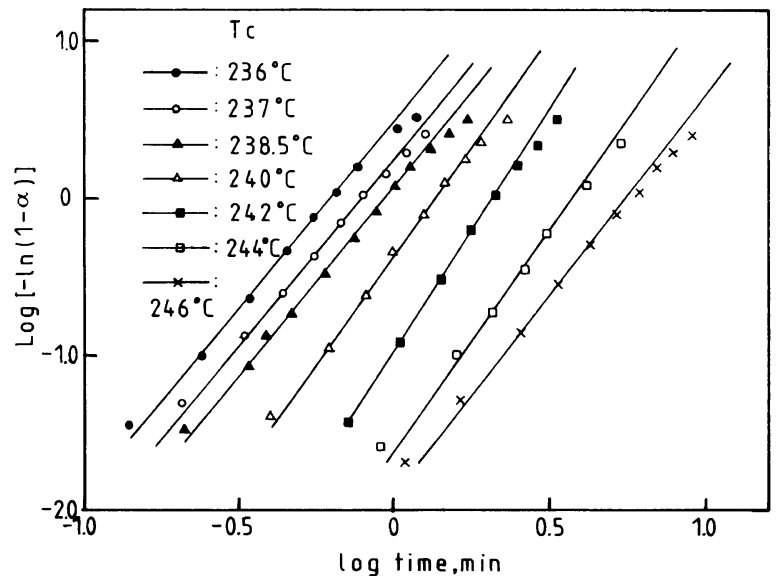

Figure 4. Plot of $\log [-\ln (1-\alpha)] v s$. $\log t$ at different $T_{\mathrm{c}}$ s for pure nylon 66.

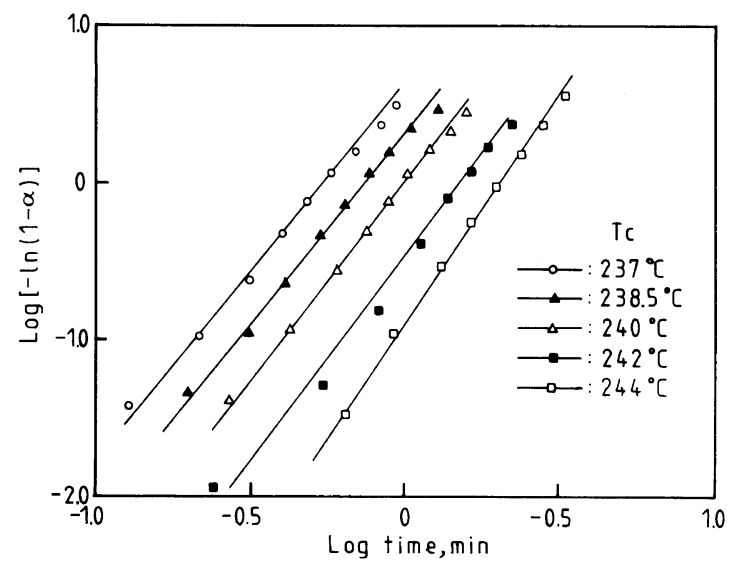

Figure 5. Plot of $\log [-\ln (1-\alpha)] v s . \log t$ at different $T_{\mathrm{c}} \mathrm{s}$ for PEI 15 .

are observed in PEI 5, PEI 25, and PEI 50.

Theories of surface nucleation have been modified to account for the effects of the non-crystallizable component on the linear growth rate of crystals developing in undercooled homogeneous blends. ${ }^{18-21}$ At present, because of lack of information on diffusion constants in polymer blends, the equation commonly used to describe the linear growth kinetics is, ${ }^{22}$

$$
\begin{aligned}
G= & \varphi_{2} G_{o} \exp \left\{\frac{-U}{R\left[C_{2}+T-T_{\mathrm{g}}(\varphi)\right]}\right\} \\
& \times \exp \left\{\frac{-r b_{\mathrm{o}} \sigma \sigma_{\mathrm{e}} T_{\mathrm{m}}^{\mathrm{o}}(\varphi)}{\left[k f \Delta H_{\mathrm{m}}^{\mathrm{o}} T \Delta T(\varphi)\right]}\right\} \\
& \times \exp \left\{\frac{2 \sigma T_{\mathrm{m}}^{\mathrm{o}} \operatorname{in} \varphi_{2}}{\left[b_{\mathrm{o}} f \Delta H_{\mathrm{m}}^{\mathrm{o}} \Delta T(\varphi)\right]}\right\}
\end{aligned}
$$

where $\varphi_{2}$ is the volume fraction of a crystallizable polymer, $U$ activation energy for transport of a segment to the crystal front through the undercooled melt, for which the glass transition temperature is composition dependent, $T_{\mathrm{g}}(\varphi)$, and $C_{2}$ a constant usually assumed as $50^{\circ} \mathrm{C}, f$ a correction factor for the temperature dependence of the enthalpy of fusion and expressed as $f=2 T /\left[T_{\mathrm{m}}^{\mathrm{o}}(\varphi)+T\right]$, and $k$ Boltzmann's constant. $\sigma$ and $\sigma_{\mathrm{e}}$ are the lateral and fold surface free energies for the developing crystals, respectively, and $b_{0}$ the layer thickness, $r$ a parameter characteristic of the growth 
Table I. Isothermal crystallization data for blends of nylon 66/PEI

\begin{tabular}{|c|c|c|c|c|}
\hline Code & $T_{\mathrm{c}} /{ }^{\circ} \mathrm{C}$ & $Z / \min ^{-n}$ & $n$ & $t_{1 / 2}(\alpha=0.5) / \mathrm{min}$ \\
\hline \multirow[t]{5}{*}{ PEI 0} & 237 & 4.17 & 2.6 & 0.48 \\
\hline & 238.5 & 2.42 & 2.6 & 0.57 \\
\hline & 240 & 1.66 & 2.6 & 0.74 \\
\hline & 242 & 0.21 & 3.0 & 1.31 \\
\hline & 244 & 0.13 & 3.0 & 1.75 \\
\hline \multirow[t]{5}{*}{ PEI 5} & 237 & 1.95 & 2.5 & 0.63 \\
\hline & 238.5 & 1.15 & 2.4 & 0.84 \\
\hline & 240 & 0.83 & 2.4 & 0.92 \\
\hline & 242 & 0.20 & 2.7 & 1.57 \\
\hline & 244 & 0.038 & 3.0 & 2.63 \\
\hline \multirow[t]{6}{*}{ PEI 10} & 237 & 1.74 & 2.4 & 0.65 \\
\hline & 238.5 & 0.76 & 2.7 & 0.97 \\
\hline & 240 & 0.42 & 2.7 & 1.15 \\
\hline & 242 & 0.12 & 3.0 & 1.67 \\
\hline & 244 & 0.035 & 2.9 & 2.75 \\
\hline & 246 & 0.030 & 2.3 & 5.00 \\
\hline \multirow[t]{7}{*}{ PEI 15} & 236 & 3.24 & 2.4 & 0.53 \\
\hline & 237 & 1.82 & 2.4 & 0.67 \\
\hline & 238.5 & 1.20 & 2.4 & 0.82 \\
\hline & 240 & 0.43 & 2.8 & 1.17 \\
\hline & 242 & 0.11 & 3.0 & 1.85 \\
\hline & 244 & 0.023 & 2.9 & 3.3 \\
\hline & 246 & 0.012 & 2.6 & 4.9 \\
\hline \multirow[t]{5}{*}{ PEI 25} & 237 & 3.89 & 3.0 & 0.49 \\
\hline & 238.5 & 1.82 & 2.8 & 0.66 \\
\hline & 240 & 0.93 & 2.6 & 0.86 \\
\hline & 242 & 0.34 & 3.0 & 1.15 \\
\hline & 244 & 0.20 & 2.7 & 1.67 \\
\hline \multirow[t]{5}{*}{ PEI 50} & 237 & 2.15 & 2.4 & 0.56 \\
\hline & 238.5 & 1.45 & 2.6 & 0.70 \\
\hline & 240 & 0.61 & 2.7 & 1.09 \\
\hline & 242 & 0.17 & 3.0 & 1.56 \\
\hline & 244 & 0.11 & 2.8 & 2.00 \\
\hline
\end{tabular}

regime: $r=4$ in regimes I and III, $r=2$ in regime II. $\Delta T(\varphi)=T_{\mathrm{m}}^{\mathrm{o}}(\varphi)-T$ is the actual undercooling experienced by the crystallizable chain in the blend.

Three main factors can be taken into account to explain the retardation of non-crystallizable PEI on the linear growth rate of nylon 66 . The dilution effect related to $\varphi_{2}$ diminishes the number of a crystallizable chain at the growing lamella front; depression of undercooling degree, $\Delta T(\varphi)$, resulting from reduction of the equilibrium melting point reduces the driving force for the crystallization; increment of $T_{\mathrm{g}}(\varphi)$ associated with the presence of mixed PEI with high $T_{\mathrm{g}}$ in nylon 66 phase decreases the mobility of a crystallizable segment. In order to maintain the crystalline lamellae growing during crystallization, the non-crystallizable polymer chain, PEI in this study, migrated in nylon 66-rich phase must be expelled ahead from the growing front of the lamellae and the crystallizable molecular chain, nylon 66 , must diffuse to attain the growing front on the lamellae. The diffusion rate of nylon 66 was reduced because of the high viscosity of PEI. The torque ratio of PEI to nylon 66, expressed as viscosity ratio, was about 27 at $300^{\circ} \mathrm{C}$ during mixing in Haake Rheocord 90 at $60 \mathrm{rpm}^{16}$

Hindrance of the rate of crystallization from the dispersed phase in which PEI is the main constituent cannot be evaluated by eq 5 , but seems to be considerable in the PEI/nylon 66 blend. Nylon 66 tends to crystallize so fast that it is not effectively quenched into an amorphous material. The isothermal crystallization ex-

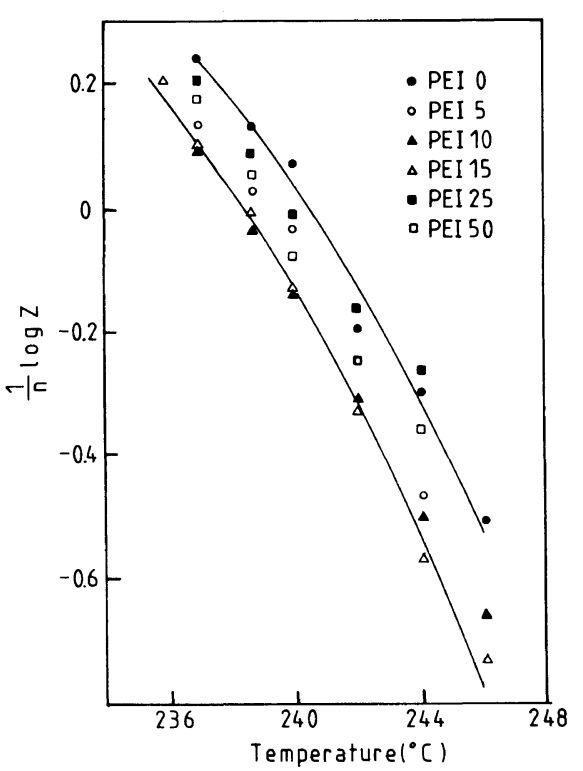

Figure 6. Plot of $1 / \mathrm{n} \log Z$ vs. $T_{\mathrm{c}}$ at various compositions for the blends of nylon 66/PEI.

periment was carried out at temperatures ranging from 237 to $250^{\circ} \mathrm{C}$. The reduction in the rate constant of crystallization by $50 \%$ in PEI 10 and PEI 15 with respect to pure nylon 66 was observed. This may be due to the influence of non-crystallizable PEI with $T_{\mathrm{g}}$ at around $230^{\circ} \mathrm{C}$. Similar conclusion has been confirmed in literature. Sakurai et al. ${ }^{23}$ and Cohen et al. ${ }^{24}$ speculate that the structure is kinetically trapped and could not attain a final equilibrium state when the crystallization process is observed by a non-crystallizable component with high $T_{\mathrm{g}}$. Pizzoli et al. concluded that the linear growth rate of spherulite is reduced by 2.5 orders of magnitude as a high $T_{\mathrm{g}}$ component reaches $50 \%$ by weight. $^{25}$

Intermolecular interactions between two components would lead to the depression of the crystallization rate. This was verified by several experimental events on the dynamic mechanical spectra. Both the secondary relaxation dispersions of PEI and nylon 66 shifted to higher temperatures and an interface relaxation was measured, ${ }^{16}$ which implies some degree of interaction between the component polymers, reducing the growth rate of crystallization because the intermolecular interaction hinders the movement of polar groups and diminishes the mixing entropy of the system. Thus, the mutual interdiffusion of two polymers will be retarded by the intermolecular force.

The effects of PEI as a crystallization nucleus on the growth rate of the spherulites of nylon 66 should be considered to explain why the linear growth rate is larger in PEI 50 and PEI 25 than those in PEI 10 and PEI 15. Added polymers and mineral filters as nucleating agents were investigated to increase the crystallization rate. $^{26-29}$ These nucleating agents may reduce the fold surface free energy of the developing crystals and the effect can be examined by eq 4 and 5 . By combining eq 4 and 5 and rearrangement: 


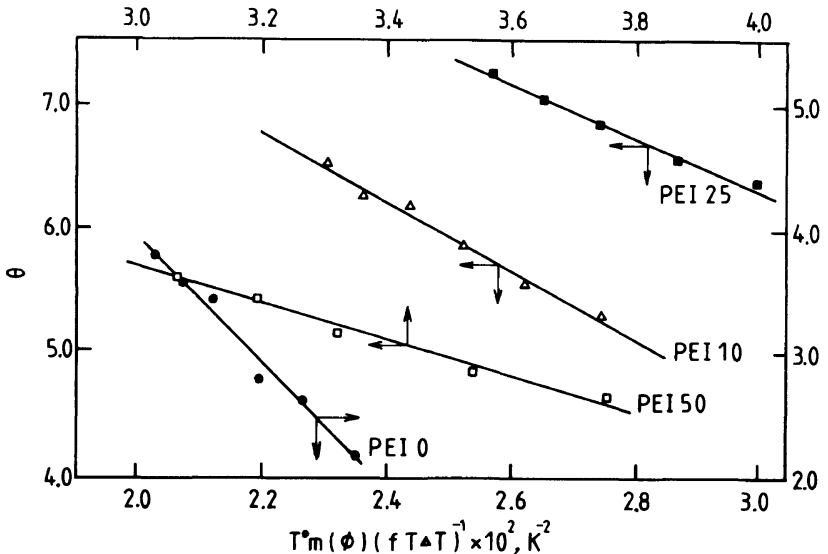

Figure 7. Plot of kinetic data according to eq 6.

Table II. Compositions and glass transition temperatures of nylon 66-rich phase in the nylon 66/PEI blends

\begin{tabular}{cccc}
\hline Code & Nylon 66/wt $\%$ & PEI $/ \mathrm{wt} \%$ & $T_{\mathbf{g}}{ }^{\circ} \mathbf{C}$ \\
\hline PEI 0 & 100 & 0 & 73 \\
PEI 5 & 96 & 4 & 78 \\
PEI 10 & 94 & 6 & 80 \\
PEI 15 & 93 & 7 & 82 \\
PEI 25 & 91 & 9 & 83 \\
PEI 50 & 91 & 9 & 83 \\
\hline
\end{tabular}

$$
\begin{aligned}
\theta= & \frac{1}{n} \ln Z+\frac{U}{R\left[C_{2}+T-T_{\mathrm{g}}(\varphi)\right]} \\
& -\left[1+\frac{2 \sigma T_{\mathrm{m}}^{\mathrm{o}}(\varphi)}{b_{\mathrm{o}} f \Delta H_{\mathrm{m}}^{\mathrm{o}} \Delta T(\varphi)}\right] \ln \varphi_{2} \\
= & \ln G_{0}-\frac{r b_{\mathrm{o}} \sigma \sigma_{\mathrm{e}} T_{\mathrm{m}}^{\mathrm{o}}(\varphi)}{k f \Delta H_{\mathrm{m}}^{\mathrm{o}} T \Delta T(\varphi)}
\end{aligned}
$$

Therefore, by plotting $\theta$ as a function of $T_{\mathrm{m}}^{\mathrm{o}}(\varphi) /$ $k f T \Delta T(\varphi)$ for each composition, one should obtain straight lines with slopes related to the surface free energies of the lamella crystals. Our experimental results are shown in Figure 7 . The parameters, $Z$ and $n$ were evaluated from Avrami analysis; $C_{2}=50^{\circ} \mathrm{C}, U=5.98 \mathrm{~kJ}$ $\mathrm{mol}^{-1}$, and $b_{0}=0.54 \mathrm{~nm}$ were taken from the literature ${ }^{13,30,31} ; T_{\mathrm{g}}(\varphi)$ and $T_{\mathrm{m}}^{\mathrm{o}}(\varphi)$ were measured from the dynamic mechanical analysis and thermal analysis, respectively. The compositions and glass transition temperatures of nylon-rich phases in the nylon 66/PEI blends are shown in Table II. ${ }^{16}$

Figure 7 shows that experimental data obey eq 6 at all compositions. From the slopes of the straight lines, the products of the lateral and fold surface free energies, $\sigma \sigma_{\mathrm{e}}$, can be calculated if the growth regime is known. Assuming that crystallization is carried out in regime II according to the experience related to the undercooling degree at about $60^{\circ} \mathrm{C}$, the values of $\sigma \sigma_{\mathrm{e}}$ are shown in Table III. Provided $T_{\mathrm{c}} \mathrm{s}$ are located in the same growth regime, the value of $r$ is a constant. The lateral surface free energy can be estimated by means of ThomasStaveley Equation ${ }^{32}$ :

$$
\sigma=\beta \Delta H_{\mathrm{m}}^{0} A_{0}^{1 / 2}
$$

where $A_{0}$ is the cross sectional area of a chain in the crystal and $\beta$ is a constant. $\sigma$ is invariable for the same
Table III. Equilibrium melting points, transition temperatures of positive and negative spherulites $\left(T_{ \pm}\right)$, and thickening factor for blends of nylon 66/PEI

\begin{tabular}{lcccc}
\hline Code & $T_{\mathrm{m}}^{\mathrm{o}} /{ }^{\circ} \mathrm{C}$ & $T_{ \pm}^{0} /{ }^{\circ} \mathrm{C}$ & $\delta$ & $\sigma \sigma_{\mathrm{e}} /\left(\mathrm{erg} \mathrm{cm}^{-2}\right)^{2}$ \\
\hline PEI 0 & 295 & 253.5 & 1.45 & 1628 \\
PEI 10 & 287 & 254.5 & 1.50 & 935 \\
PEI 25 & 281 & 255.5 & 1.64 & 729 \\
PEI 50 & 273 & 258.0 & 1.90 & 488
\end{tabular}

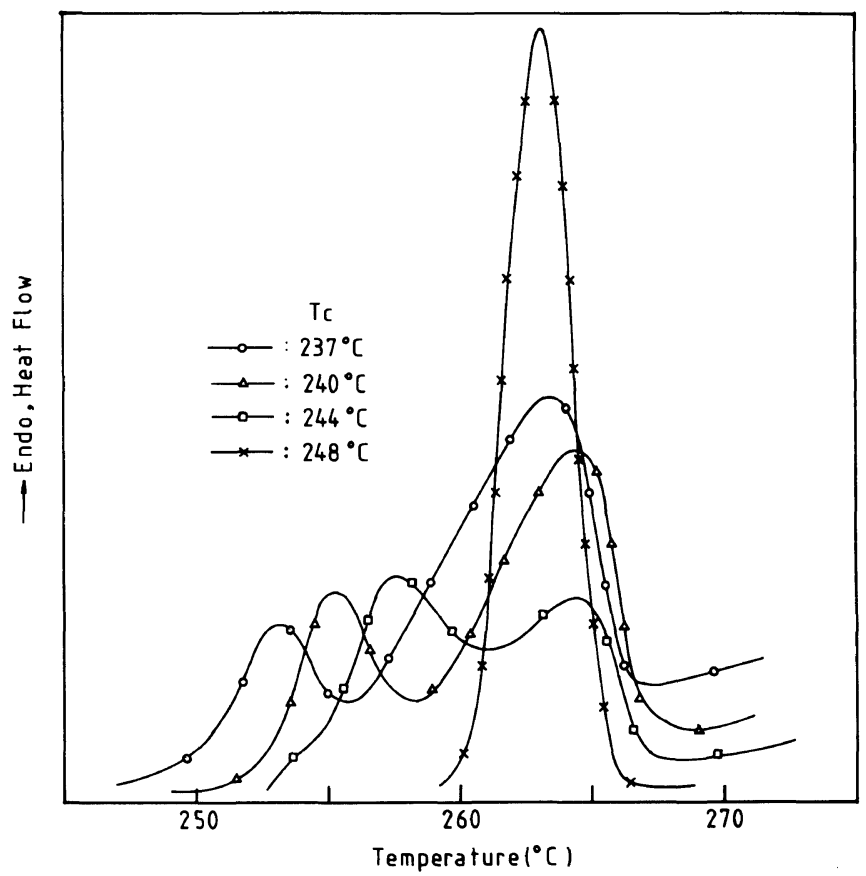

Figure 8. DSC curves of pure nylon 66 obtained with heating from $T_{\mathrm{c}}$ after isothermally crystallized at different $T_{\mathrm{c}} \mathrm{s}$.

nylon 66 crystals in the blends with various compositions, therefore, the difference in the slopes in Figure 7 is responsible for the fold surface free energy, $\sigma_{\mathrm{e}}$. From the results in Table III, it is concluded that the incorporation of PEI reduces the fold surface free energy of the crystals of nylon 66 . Therefore, the growth rate of the spherulites should be enhanced with amount of PEI in the blends. In nylon 66/PEI blends, $\sigma \sigma_{\mathrm{e}}$ decreased by $55 \%$ and $70 \%$ in PEI 25 and PEI 50 , respectively.

The isothermally crystallized crystals of pure nylon 66 and its blends with PEI from the melt consistently show a double-melting behavior. Plots of melting temperature, $T_{\mathrm{m}}$, as a function of $T_{\mathrm{c}}$ with heating in DSC from $T_{\mathrm{c}}$ are shown in Figures 8 and 9 for pure nylon 66 and PEI 25, respectively. In the double-melting curve, only the lower melting endotherm was found to increase with $T_{\mathrm{c}}$, whereas the higher endotherm was thermally insensitive as in the case of those reported. ${ }^{22,33}$ Consequently, the higher endotherm was attributed to a reorganization process associated with the forming of the negative spherulites.

The crystal structure and morphology of nylon 66 have been investigated thoroughly. ${ }^{13}$ Only a stable crystal structure of nylon 66 crystallized from the melt is $\alpha$-phase. The double-melting behavior is not related to two forms of polymorph but to the types of spherulites characterized from optical microscopic studies. The positive spherulites were formed exclusively when the melt is cooled below 


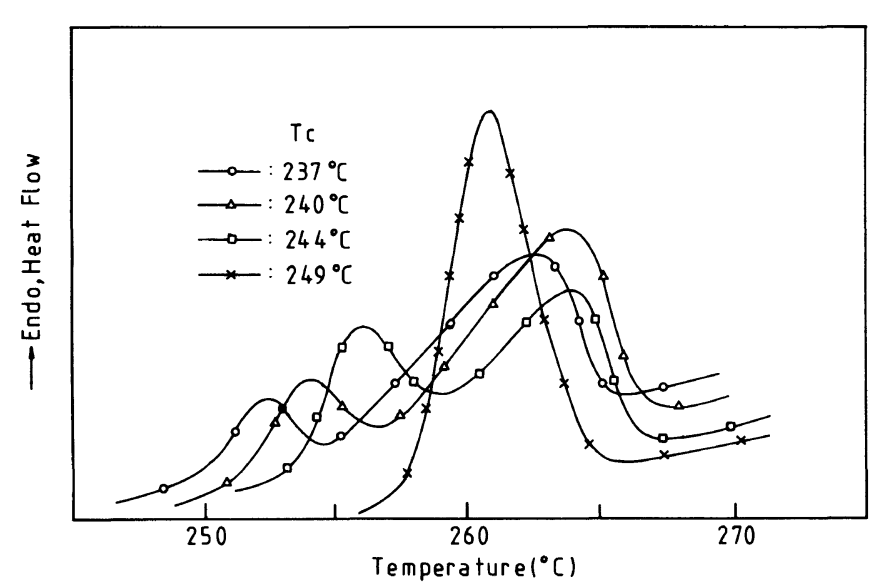

Figure 9. DSC curves of PEI 25 obtained with heating from $T_{\mathrm{c}}$ after isothermally crystallized at different $T_{\mathrm{c}} \mathrm{s}$.

$250^{\circ} \mathrm{C}$. The negative spherulites grow at 250 to $270^{\circ} \mathrm{C}$ and are always accompanied by spherulitic aggregates. When the sample is held between 250 and $265^{\circ} \mathrm{C}$, the positive spherulites melt entirely and recrystallize to form negatively birefringent spherulites. The temperature boundary, about $250^{\circ} \mathrm{C}$, below which positive spherulites are formed and above which negative spherulites develop has been defined. ${ }^{13}$ However, the optical microscope is not an exact thermal analysis instrument. We develop a new method to estimate the transition temperature of positive/negative spherulites that is responsible for the point of intersection between $T_{\mathrm{m}_{1}} v s . T_{\mathrm{c}}$ and $T_{\mathrm{m}_{2}}$ vs. $T_{\mathrm{c}}$ lines shown in Figure 10 . The transition temperature increases with increasing the content of PEI in the blends. It is $253.5^{\circ} \mathrm{C}$ for pure nylon $66,3.5^{\circ} \mathrm{C}$ higher than that observed by optical microscope. ${ }^{13}$

In most cases, the transition temperature measured by thermal method is higher than the optically observed value due to the difficulty in attaining the thermal equilibrium. We deduce that negative spherulites may be formed at lower $T_{\mathrm{c}}$ and content depends on $T_{\mathrm{c}}$ considerably. On DSC heating traces, the single melting peak lower than $T_{\mathrm{m}_{2}}$, but higher than $T_{\mathrm{m}_{1}}$ on the double-melting curves was observed experimentally in the samples isothermally crystallized at about $250^{\circ} \mathrm{C}$ as shown in Figures 8 and 9. This may result from the mixture of the growth patterns of positive and negative spherulites. $^{13}$

The variation of double-melting behavior on the DSC heating scans of the isothermally crystallized blends means that the lower endotherm occurs at a temperature about $15^{\circ} \mathrm{C}$ above $T_{\mathrm{c}}$, whereas the higher endotherm appears at approximately $264^{\circ} \mathrm{C}$ and relatively insensitive to $T_{\mathrm{c}}$. The heat of fusion of the lower endotherm is found to increase with $T_{\mathrm{c}}$ while that of the higher endotherm to decrease. This indicates that the reorganization ability after the previous melting is enhanced with the reduction of $T_{\mathrm{c}}$. This is understandable, since the crystals formed at lower $T_{\mathrm{c}}$ tend to have higher content of small defective spherulites. Perhaps most of them are positive spherulites with branched fibril structures. After the initial melting, crystalline domains may still exhibit large mobility and sufficient molecular ordering that would facilitate reorganization. In contrast, the crystals formed at higher $T_{\mathrm{c}}$ are larger and more perfect positive spherulites that

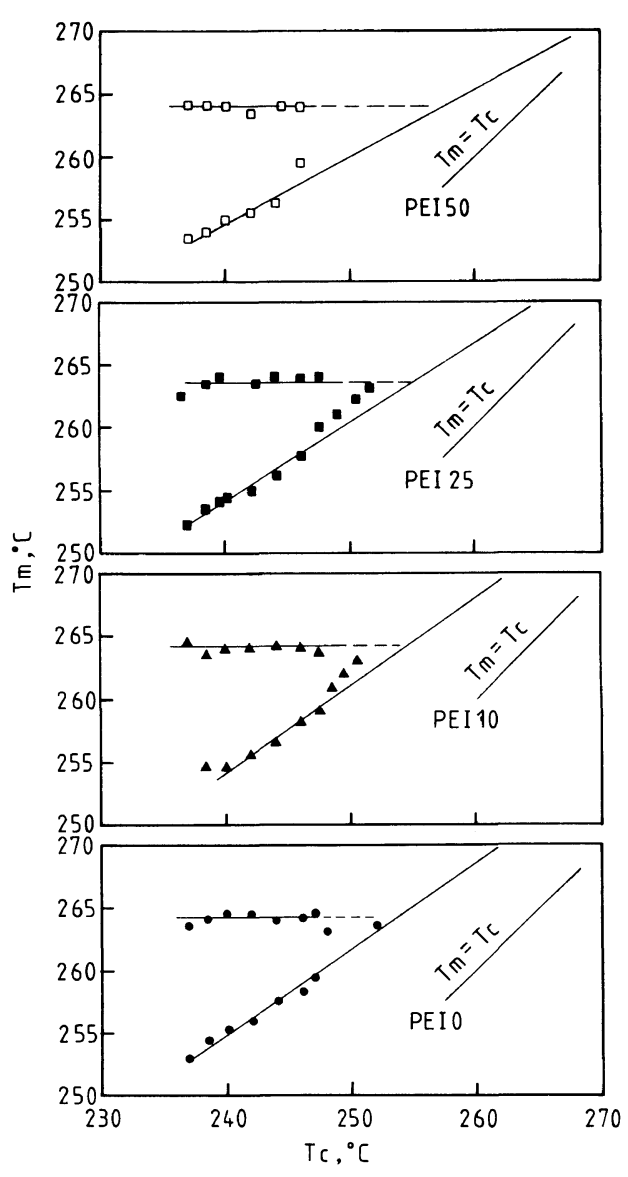

Figure 10. Dependence of melting points and transition temperatures of positive/negative spherulites on crystallization temperature and composition of blends of nylon 66/PEI.

may lead to a lower mobility upon pre-melting that often hinders reorganization. Magill et al. observed similar results by heating the pure nylon 66 isothermally crystallized in various solvents. ${ }^{30}$

The relationship between the melting temperature and the lamellae thickness of the crystals, $L$, reads:

$$
T_{\mathrm{m}}=T_{\mathrm{m}}^{\mathrm{o}}\left[1-\frac{2 \sigma_{\mathrm{e}}}{\Delta H_{\mathrm{m}}^{\mathrm{o}} L}\right]
$$

The crystals with thicker lamellae, i.e., bigger fold chain length are formed at higher $T_{\mathrm{c}}$ or during reorganization. These results are associated with optical observations because the negative spherulites have more stable and perfect crystal structures. These conclusions are confirmed not only in neat nylon 66 but also in the blends according to our study.

By studying the melting behavior of the samples isothermally crystallized from the melt, it is deduced that the lower melting peaks on the DSC heating trace should be useful in the Hoffman-Weeks approach to evaluate the equilibrium melting point. ${ }^{34,35}$ Figure 10 reveals the plots of $T_{\mathrm{m} 1}$ as a function of $T_{\mathrm{c}}$ for some compositions investigated. The equilibrium melting point, $T_{\mathrm{m}}^{\mathrm{o}}$, of nylon 66 and blends are summarized in Table III, together with the thickening factor, $\delta$, calculated from the slopes of the lines in Figure 10 according to eq 9 : 


$$
T_{m}=T_{\mathrm{m}}^{\mathrm{o}}\left(1-\frac{1}{\delta}\right)+\frac{T_{\mathrm{c}}}{\delta}
$$

Our results of $T_{\mathrm{m}}^{\mathrm{o}}$ for pure nylon 66 are $6^{\circ} \mathrm{C}$ lower than that reported in literature. ${ }^{30,31,36}$ The differences in the molecular weight and the variation in chemical regularity might lead to effect on $T_{\mathrm{m}}^{\mathrm{o}}$. The remarkable effect of PEI on the $T_{\mathrm{m}}^{\mathrm{o}}$ of nylon 66 is observed. $T_{\mathrm{m}}^{\mathrm{o}}$ decreases by $22^{\circ} \mathrm{C}$ for PEI 50 with respect to the pure nylon 66 .

Since negative and positive spherulites have different melting temperatures, some single melting peaks located between $T_{\mathrm{m}_{1}}$ and $T_{\mathrm{m}_{2}}$ should result from the mixtures of two types of spherulites. They may be responsible for the overlap of two melting processes that may lead to incorrect extrapolation from $T_{\mathrm{m}} v s . T_{\mathrm{c}}$ data. These experimental points deviated from the $T_{\mathrm{m}}-T_{\mathrm{c}}$ straight lines in Figure 10 can be observed clearly and all are shown in higher $T_{\mathrm{c}}$. Hoffman-Weeks procedure for obtaining the $T_{\mathrm{m}}^{\mathrm{o}}$ is fraught with assumptions. It is necessary to choose $T_{\mathrm{c}}$ carefully in a limited range of temperatures. The range of $T_{\mathrm{c}}$ from 238.5 to $246^{\circ} \mathrm{C}$ is suitable in our case where the negative spherulites are seldom formed during crystallization and $T_{\mathrm{c}}$ close to the melting temperature.

\section{CONCLUSIONS}

The blends of PEI and nylon 66 were prepared with the PEI composition range up to $50 \mathrm{wt} \%$ by melt mixing in an internal mixer. The crystallization behavior of the polymer blends was studied by DSC as a function of composition and isothermal crystallization temperature. The slow crystallization rate was observed in the PEI 10 and 15 compositions, which might result from the increased interaction between the components. A transition temperature where positively birefringent spherulites disappear and negative birefringent spherulites develop increased with increasing the content of PEI in the blends. A suitable range of isothermally crystallized temperatures, $238.5-246^{\circ} \mathrm{C}$, is suggested for determining the equilibrium melting points by the Hoffman-Weeks approach.

Acknowledgment. The authors thank the Ministry of Sciences and Technology of Korea for supporting this research.

\section{REFERENCES}

1. R. T. Woodhams, Polym. Eng. Sci., 25, 446 (1985).

2. R. O. Johnson and E. O. Teutsch, Polym. Compos., 4, 162 (1983).
3. R. J. Karcha and R. S. Porter, J. Polym. Sci., Part B: Polym. Phys. Ed., 31, 821 (1993).

4. M. R. Nobil, D. Aciermo, L. Incarnato, E. Amendole, L. Nicolais, and C. Carfagna, J. Appl. Polym. Sci., 41, 2723 (1990).

5. G. Grevencoeur and G. Groeninckx, Macromolecules, 24, 1190 (1991).

6. K. Liang, J. Grebowicz, E. Valles, F. E. Karasz, and W. J. MacKnight, J. Polym. Sci., Part B: Polym. Phys. Ed., 30, 465 (1992).

7. S. Choe, W. J. MacKnight, and F. E. Karasz, in "Polyimide: Mater., Chem. Charact., 3rd Proc. Int. Conf. Polyimides," C. Feger, M. M. Khojasteh, and J. E. McGrath, Ed., Elsevier Science Publishers, Amsterdam, 1989, p 25.

8. H. W. Starkweather, Jr., P. Zoller, and G. A. Jones, J. Polym. Sci., Polym. Phys. Ed., 22, 1615 (1984).

9. J. P. Bell, P. E. Slade, and J. H. Dumbleton, J. Polym. Sci., Part A-2, 6, 1773 (1968).

10. D. C. Vogelsong, J. Polym. Sci., Part A, 1, 1055 (1963).

11. L. G. Roldan and H. S. Kaufman, J. Polym. Sci., Part B, 1, 603 (1963)

12. J. H. Magill, J. Polym. Sci., Part A-2, 7, 123 (1969).

13. E. S. Clark and F. C. Wilson, in "Nylon Plastics," M. I. Kohan, Ed., John Wiley \& Sons, New York, N.Y., 1973, p 271.

14. M. Todoki and T. Kawaguchi, J. Polym. Sci., Polym. Phys. Ed., 15, 1067 (1977).

15. E. Martuscelli, F. Riva, C. Sellitti, and C. Silvestre, Polymer, 26, 270 (1985).

16. K.-Y. Choi, S.-G. Lee, J. H. Lee, and J. J. Liu, Polym. Eng. Sci., 35, 1643 (1995).

17. M. Dole and B. Wunderlich, Makromol. Chem., 34, 29 (1959).

18. J. Boon and J. M. Azcue, J. Polym. Sci., Part A-2, 6, 885 (1968).

19. C. J. Ong and F. P. Price, J. Polym. Sci., Polym. Symp., 63, 59 (1978).

20. T. T. Wang and T. Nishi, Macromolecules, 10, 421 (1977).

21. G. C. Alfonso and T. P. Russell, Macromolecules, 19, 1143 (1986).

22. G. C. Alfonso, V. Chiappa, J. J. Liu, and E. R. Sadiku, Eur. Polym. J., 27, 795 (1991).

23. K. Sakurai, W. J. MacKnight, D. J. Lohse, D. N. Schulz, and J. A. Sissano, Macromolecules, 27, 4941 (1994).

24. R. E. Cohen, P. L. Cheng, K. Douzinas, P. Kofinas, and C. V. Berney, Macromolecules, 23, 324 (1990).

25. M. Pizzoli, M. Scandola, and G. Ceccorulli, Macromolecules, 27, 4755 (1994).

26. J. J. Liu, H. R. Zhou, Q. P. Guo, and G. J. Qu, J. Appl. Polym. Sci., 47, 2111 (1993).

27. B. De Carvalho and R. E. S. Bretas, J. Appl. Polym. Sci., 55, 233 (1995).

28. C. F. Ou and C. C. Lin, J. Appl. Polym. Sci., 54, 1223 (1994).

29. D. H. Lee and K. B. Yoon, J. Appl. Polym. Sci., 54, 1507 (1994).

30. J. H. Magill, M. Girolamo, and A. Keller, Polymer, 22, 43 (1981).

31. J. D. Hoffman, G. T. Davis, and J. I. Lauritzen, Jr., in "Treatise on Solid State Chemistry," Vol. 3, N. B. Hannay, Ed., Plenum Press, New York, N.Y., 1976, Chapter 7.

32. D. G. Thomas and L. A. K. Staveley, J. Chem. Soc., 4569 (1952).

33. B. S. Hsiao, K. H. Gardner, and S. Z. D. Cheng, J. Polym. Sci., Part B: Polym. Phys. Ed., 32, 2585 (1994).

34. J. D. Hoffman and J. J. Weeks, J. Chem. Phys., 37, 1732 (1962).

35. J. D. Hoffman, SPE Trans., 4, 315 (1964).

36. A. Xenopoulos and B. Wunderlich, J. Polym. Sci., Part B: Polym. Phys. Ed., 28, 2271 (1990). 